\title{
Activation of Jordanian Ore Bentonite by Sodium Carbonates
}

\author{
Shakhatreh K. Saleh*, Mehaysen A. Mahasneh \\ Al-Huson University College, Al-Balq'a Applied University, Irbid, Jordan \\ Email: 'Shakhatreh.Saleh@yahoo.com,mahsneh2008@hotmail.com
}

Received 26 September 2015; accepted 15 November 2015; published 18 November 2015

Copyright (C) 2015 by authors and Scientific Research Publishing Inc.

This work is licensed under the Creative Commons Attribution International License (CC BY). http://creativecommons.org/licenses/by/4.0/

(c) (i) Open Access

\section{Abstract}

The Hashemite Kingdom of Jordan has a large reserve of raw Bentonite in the area of Ain Al-Baida at Basin of Al-Azraq city that has not activated yet to become valid as drilling mud. The Ore Ain AL-Baida Bentonite was investigated and activated by $\mathrm{Na}_{2} \mathrm{CO}_{3}$. The products were investigated by chemical analysis, $X$-Ray Diffraction, rheological properties and free swelling index with clay fraction. It was observed that the activities clay ranged between $0.98<\mathrm{AC}<1.48$ medium to high content of clay minerals. In addition, it was determined the Atterberg limits, the results of plasticity chart and relation between index and clay fraction. This means that the amount of the attracted water will be suitable influenced by the clay that is present in Ore Ain Al-Baida bentonite. The liquid limit was ranged between $83 \%$ to $140 \%$, and plastic limit ranged between $39 \%-48 \%$. Also, rheological properties (apparent viscosity, plastic viscosity), gel strength, yield point, filtrate loss. These properties have been compared with those standard specifications properties required for the drilling fluid in order to know the appropriate circumstances to activate the Bentonite ore of Ain Al Baida at Azraq basin to become close to the standard specifications required for the drilling fluids, the ratio between Y.P/P.V was ranged 0.88 to 1.21, it is meant that the behavior of drilling fluids confirms the Bingham plastic and power-law rheological models using fine grinding of bentonite mixture with $3 \%$ - $6 \%$ concentration of sodium carbonate powder.

\section{Keywords}

Activation of Bentonite, Ain Al-Baida, Free Swelling, Liquid Limit, Sodium Carbonate

\section{Introduction}

So far, the ore bentonite of Ein Al-Baida basin has not been used economically because its existence as raw clay from non active smectite group which is not conforming to the specifications of the drilling fluid for wells of oil "Corresponding author.

How to cite this paper: Saleh, S.K. and Mahasneh, M.A. (2015) Activation of Jordanian Ore Bentonite by Sodium Carbonates. Journal of Minerals and Materials Characterization and Engineering, 3, 477-487.

http://dx.doi.org/10.4236/immce.2015.36050 
and gas that usually consists of sodium bentonite.

Studies were conducted at Ain Al-Baida to determine the mineral composition using analysis by X-ray diffraction for metal crude where it displayed montmorillonite metal a kind of binary charge calcium metal or magnesium calcium. It is noted here that the offset value of the first major reflection was up to 15 angstrom, and in addition there was non-clay minerals such as quartz, calcite, dolomite [1]-[7]. The aim of this study was to point out the possibility of activating ore bentonite of Ain Al-Beida utilizing sodium carbonate powder and to employ the energy of fine grinding raw bentonite in a dry way. The main axis of reference in this study depends on the sampling of Egyptian Commercial Bentonite adopted corresponding to the specifications of bentonite used as a liquid mud of wells of known properties as an essential reference to all tests, as well as samples of Ain Al-Beida bentonite that have been activated.

\section{Materials and Method}

Study area and collection of samples: Raw bentonite were collected from the area of Ain Al-Baida Basin of Al-Azraq city. Samples were collected from different locations of the area at different depths, as illustrated in the following Figure 1.

Samples were crushed by a Jaw crasher, then grinded by a disc mill and then sieved. The samples were washed and dried at $100^{\circ} \mathrm{C}$, activated by sodium carbonate at different concentrations. Activated bentonite were tested and characterized.

Material Used: Sodium Carbonate, bentonite ore.

\section{Experiments}

1) Prepration of raw bentonite.

The area of the study Ain Al-Baida is located at $120 \mathrm{~km}$ to the east of Amman-Jordan. Samples were crushed by a Jaw crasher, grinded by disc mill and then sieved. The average particle size was (90, 75, 63, 45, 38 and 25 $\mu \mathrm{m})$. Drying the samples in an oven at $100^{\circ} \mathrm{C}$.

2) Preparation of sodium carbonate.

3) Activation of bentonite.

The sample was divided into four portions each weighing $100 \mathrm{~g}$ and to each portion, different percentage of $\mathrm{Na}_{2} \mathrm{CO}_{3}$ were added. The percentage ranges from $1.5 \%$ to $6 \%$.

4) Characterization of activated bentonite.

Physical and rheological properties were measured, such as: density, apparent viscosity, gel strength, lost filtrate, free swell index, plasticity index, liquidity guide and ion exchange capacity. X-Ray diffraction was used too.

The chemical analysis on the main constituent elements of raw bentonite by XRF is shown in Table 1 . The samples were prepared of size $75 \mathrm{~mm}$ and activated by sodium carbonate at different concentrations.

\section{Results of Practical Experience}

Depending on results of the above experiments we conclude the following:

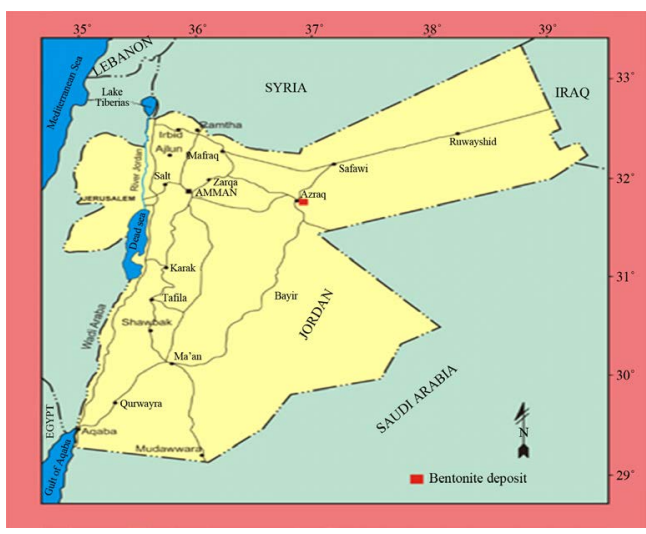

Figure 1. Location of the study area. 
Table 1. Chemical analysis of raw bentonite.

\begin{tabular}{cccccccccccc}
\hline Sample & $\mathrm{Fe}_{2} \mathrm{O}_{3}$ & $\mathrm{MnO}$ & $\mathrm{TiO}_{2}$ & $\mathrm{CaO}$ & $\mathrm{K}_{2} \mathrm{O}$ & $\mathrm{P}_{2} \mathrm{O}_{5}$ & $\mathrm{SiO}_{2}$ & $\mathrm{Al}_{2} \mathrm{O}_{3}$ & $\mathrm{MgO}$ & $\mathrm{Na}_{2} \mathrm{O}$ & L.O.I (\%) \\
\hline Sample 1 & 7.366 & 0.062 & 1.413 & 1.607 & 2.345 & 0.046 & 46.202 & 12.087 & 2.496 & 5.396 & 21.0 \\
Sample 2 & 6.759 & 0.063 & 1.417 & 3.318 & 2.265 & 0.083 & 49.683 & 11.026 & 2.55 & 5.166 & 17.7 \\
Sample 3 & 6.751 & 0.051 & 1.202 & 1.489 & 2.741 & 0.036 & 50.339 & 11.099 & 3.583 & 5.542 & 17.599 \\
Sample 4 & 6.909 & 0.054 & 1.29 & 2.004 & 2.411 & 0.047 & 49.508 & 13.319 & 2.939 & 5.667 & 16.300 \\
Sample 5 & 7.100 & 0.055 & 1.331 & 1.562 & 2.351 & 0.034 & 44.153 & 12.132 & 2.903 & 5.813 & 17.350 \\
Sample 6 & 5.889 & 0.058 & 1.274 & 1.144 & 1.927 & 0.127 & 52.637 & 9.263 & 3.009 & 3.944 & 15.25 \\
\hline
\end{tabular}

The best concentration of sodium carbonate ranges between 3\% - 6\%. Dry method gave high values of free swell to activate bentonite in which the value of the evidence of free swell index reached $26 \mathrm{ml} / 10$ grams at a concentration of $3 \%$ of sodium carbonate, while the value of evidence of free swell reached $20 \mathrm{ml} / 10$ grams at a concentration of $6 \%$ sodium carbonate. We used the relationship below that describes the modification of free swell index. Sivapullaiah et al. (1987) [8].

$$
\text { Freeswell index }=\frac{\text { size of swelled bentonite }- \text { size of dried bentonite }}{\text { size of dried bentonite }} \times 100
$$

where $V$ volume of swelled bentonites, $V_{\mathrm{o}}$ the volume of dry soil, $F_{s}$ the percentage of swelling evidence, and we have

$$
\begin{gathered}
\text { Modified free swell index }=\frac{v-v_{0}}{v_{0}} \times 100 \\
\qquad v_{0}=\frac{w_{s}}{G_{s} \gamma_{w}} \times 100
\end{gathered}
$$

where $W_{s}$ stands for the weight of dry soil after drying in the oven, $G_{s}$ the specific gravity dried bentonite (solids), $\gamma_{w}$ the unit weight of water.

Depending on modified free swell index these values the variation in free swell index depends in concentration of sodium carbonate these values of free swelling is classified as very high ability of the swell to the quality of ore solids bentonite classified as in Table 2 [9].

Regarding the standard specifications of swelling sodium bentonite we find that one gram of dried bentonite swells six times its weight in water [10]. Measuring the size of the sediment swell against gradual concussion, it shows that the clay and that appears and gives the best hndicaters for the energy swelling of clay soil. Fine milling is the best condition to activate bentonite, more than the coarse milling for size effective particles because the surface area is bigger. Egyptian Commercial bentonite is the basis for comparison with Ain Al-Baida bentonite with addition of sodium carbonate. Analysis of rheological properties of Ain Al-Baida bentonite activated by sodium carbonate with addition of chemicals such as caustic soda, carboxyl methyl cellulose low and high viscosity, enhanced bentonite and distilled water to prepare the samples and to test them using Fan viscometer device and Filter press for measuring filtrate losses.

\section{Discussion and Analysis of Results}

Increase in modified free swell index with addition of sodium carbonate and milling due to the following reasons:

\subsection{Dry Grinding Results}

To increase the surface area and blanks interfaces thus providing portability fusion, coalition and stability of sodium compound, dry grinding as done for dented samples This result was increasing the susceptibility of granular bentonite to absorb water and therefore this property increases with increment in sodium carbonate percentage up 
Table 2. Swelling potential based on the modified free swell index.

\begin{tabular}{cc}
\hline Modified free swell index & Swelling potential \\
2.5 & Negligible \\
2.5 to 10 & Moderate \\
10 to 20 & high \\
20 & Very high \\
\hline
\end{tabular}

to $6 \%$, there after the modified free swell index will start decreasing. That means the perfect percentage of sodium carbonate to be added to the dried ore bentonite powder is $3 \%-6 \%$ in order to obtain hydration cations and water molecules as shown in Table 2 [9].

\subsection{Grained Gradation Results}

To determine the percentages of different sizes (ASTM D422) [11] consisting of the sample through sieve analysis for seize parts on sieve No. $200(75 \mu \mathrm{m})$ and grain size analysis was done to use scale gravity hydrometer for the parts passing sieve No. $200(75 \mu \mathrm{m})$. The standard minimum passing through the sieve was $96.26 \%$ and the determined values was $100 \%$ illustrated in Table 3. This experience in determining the ratios of different sizes that soil consist and foremost of which is the proportion of sand and materials clay and other materials as well as draw a gradient curve as in Figure 2.

Experiment of gradient grained was conducted on five samples of bentonite after treatment by grinding with addition of sodium carbonate as we can see the results from sieve analysis in Table 3 shown the clay content (53.63\%, 65.56\%, 68.12\%, 74.13\%) that confirm the capability of clay minerals (Raw bentonite) is often employed to give a guide to its influences the physical properties, and its magnitude is also factor to be considered in assessing the origin of these properties such as cation exchange capacity and diffusion processes of charged and uncharged molecules.

From Table 4, it is shown that a very high clay-to-water ratio ultimately form suspensions ,which have a multitude of industrial applications ,the largest of which is as drilling mud or fluids for the rotary drilling industry.

\subsection{Addition of Sodium Carbonate}

During the smooth grinding process sodium carbonate was added and the fine grain has been grinding at (75, 63, 45, $38 \mathrm{~mm}$ ) to notice gradual volumetric granules bentonite as shown in Figure 2 and to know the activity of bentonite by measuring the size of granules $75 \mu \mathrm{m}$. The activation process increases after fine grinding process and then reaches to constant value whatever milling time increased. That means the process of fusion and coalition increases with the degree of finest until reaching a certain degree to maintain efficient fusion and coalition and here the chance foe sodium carbonate and bentonite to consort quickly. The fine particles size in bentonite is provided to colloidal, it is meant that particles are so small and the action of water molecules is enough to keep them stable in suspension, it can have a good surface area ranging between $370-487 \mathrm{~m}^{2} / \mathrm{g}$ [12], and bentonite expands, and provides a tendency of a suspension to gel after sitting for a time and then re-liquefy when it is agitated.

\subsection{Measuring Absorption and Capacity}

When measuring the amount of blue dye absorption Methylene blue capacity during the time of grinding there was a homogeneity of raw bentonite layer of all taken samples and it is found to be consistent with the results of the modified free swell index and the surface area of granules.

\subsection{XRF Results}

Chemical analysis of bentonite are presented in Table 1. In the original Ain Al-Baida bentonite, the percentage of $\mathrm{SiO}_{2}$ [23] was 56.421\%, while in the activated samples, the percentage of $\mathrm{SiO}_{2}$ Was $47.977 \%$. The decrease in percentage was an expected result after the removal of the free $\mathrm{SiO}_{2}$ by $\mathrm{Na}_{2} \mathrm{O}$ activation. The percentage of 


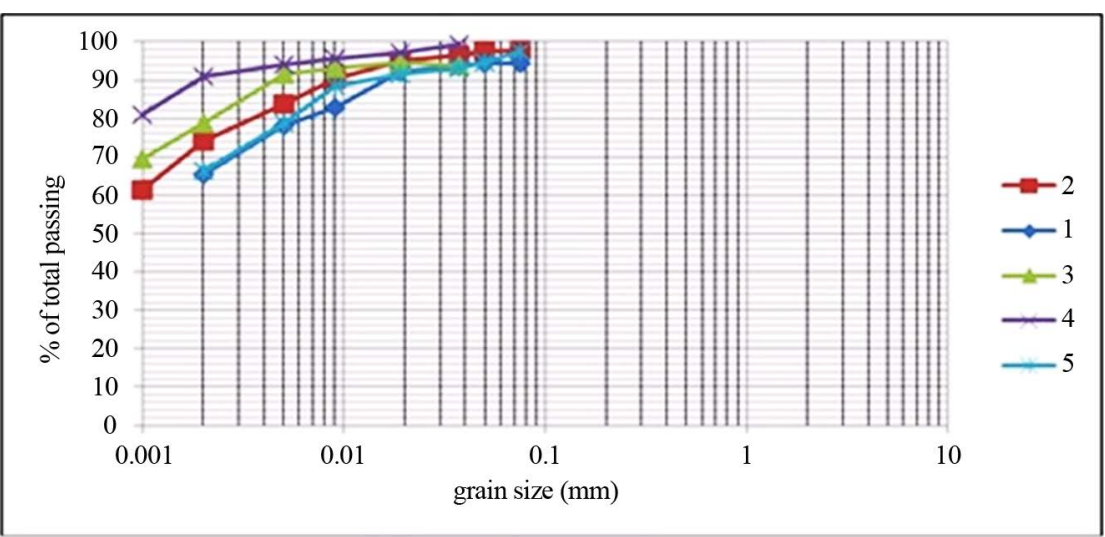

Figure 2. Sieve analysis.

Table 3. Grain size analysis.

\begin{tabular}{|c|c|c|c|c|c|c|c|c|c|c|c|c|c|}
\hline Sieve No. & $1 ”$ & $3 / 4 ”$ & $1 / 2 ”$ & $3 / 8 ”$ & $\# 4$ & $\# 8$ & $\# 16$ & \#30 & \#50 & \#100 & \#200 & Pan & Total \\
\hline \multicolumn{14}{|l|}{ Sample 1} \\
\hline Wt. Retained & 0.00 & 0.00 & 0.00 & 0.00 & 0.00 & 0.00 & 0.00 & 0.00 & 0.00 & 1.00 & 2.5 & & \\
\hline Wt. of total passing & 62.5 & 62.5 & 62.5 & 62.5 & 62.5 & 62.5 & 62.5 & 62.5 & 62.5 & 61.5 & 59.00 & & \\
\hline$\%$ of total passing & 100.00 & 100.00 & 100.00 & 100.00 & 100.00 & 100.00 & 100.00 & 100.00 & 100.00 & 98.4 & 94.4 & & \\
\hline$\%$ of total retained & 0.0 & 0.0 & 0.0 & 0.0 & 0.0 & 0.0 & 0.0 & 0.0 & 0.0 & 1.60 & 5.60 & 59.00 & 62.5 \\
\hline \multicolumn{14}{|l|}{ Sample 2} \\
\hline Wt. Retained & 0.00 & 0.00 & 0.00 & 0.00 & 0.00 & 0.00 & 0.00 & 0.00 & 0.00 & 0.00 & 2.8 & & \\
\hline Wt. of total passing & 122.4 & 122.4 & 122.4 & 122.4 & 122.4 & 122.4 & 122.4 & 122.4 & 122.4 & 122.4 & 119.6 & & \\
\hline$\%$ of total passing & 100.00 & 100.00 & 100.00 & 100.00 & 100.00 & 100.00 & 100.00 & 100.00 & 100.00 & 100.00 & 97.71 & & \\
\hline$\%$ of total retained & 0.0 & 0.0 & 0.0 & 0.0 & 0.0 & 0.0 & 0.0 & 0.0 & 0.0 & 0.0 & 2.29 & 119.6 & 122.4 \\
\hline \multicolumn{14}{|l|}{ Sample 3} \\
\hline Wt. Retained & 0.00 & 0.00 & 0.00 & 0.00 & 0.00 & 0.00 & 0.00 & 0.00 & 0.00 & 3 & 4.6 & & \\
\hline Wt. of total passing & 119 & 119 & 119 & 119 & 119 & 119 & 119 & 119 & 119 & 116 & 111.4 & & \\
\hline \% of total passing & 100.00 & 100.00 & 100.00 & 100.00 & 100.00 & 100.00 & 100.00 & 100.00 & 100.00 & 97.48 & 93.61 & & \\
\hline$\%$ of total retained & 0.0 & 0.0 & 0.0 & 0.0 & 0.0 & 0.0 & 0.0 & 0.0 & 0.0 & 2.52 & 6.39 & 111.4 & 119 \\
\hline \multicolumn{14}{|l|}{ Sample 4} \\
\hline Wt. Retained & 0.00 & 0.00 & 0.00 & 0.00 & 0.00 & 0.00 & 0.00 & 0.00 & 0.00 & 0.0 & 0.7 & & \\
\hline Wt. of total passing & 119 & 119 & 119 & 119 & 119 & 119 & 119 & 119 & 119 & 116 & 104 & & \\
\hline$\%$ of total passing & 100.00 & 100.00 & 100.00 & 100.00 & 100.00 & 100.00 & 100.00 & 100.00 & 100.00 & 97.48 & 99.33 & & \\
\hline$\%$ of total retained & 0.0 & 0.0 & 0.0 & 0.0 & 0.0 & 0.0 & 0.0 & 0.0 & 0.0 & 111.4 & 0.67 & 104 & 104.7 \\
\hline \multicolumn{14}{|l|}{ Sample 5} \\
\hline Wt. Retained & 0.00 & 0.00 & 0.00 & 0.00 & 0.00 & 0.00 & 0.00 & 0.00 & 0.00 & 0.00 & 2.6 & & \\
\hline Wt. of total passing & 107.8 & 107.8 & 107.8 & 107.8 & 107.8 & 107.8 & 107.8 & 107.8 & 107.8 & 107.8 & 105.2 & & \\
\hline \% of total passing & 100.00 & 100.00 & 100.00 & 100.00 & 100.00 & 100.00 & 100.00 & 100.00 & 100.00 & 100.00 & 97.59 & & \\
\hline$\%$ of total retained & 0.0 & 0.0 & 0.0 & 0.0 & 0.0 & 0.0 & 0.0 & 0.0 & 0.0 & 0.0 & 2.41 & 105.2 & 107.8 \\
\hline
\end{tabular}


Table 4. Summery analysis of bentonite after treatment by sodium carbonate.

\begin{tabular}{ccccc}
\hline Sample no. & sodium carbonate & Sand & Silt & Clay \\
\hline 1 & $6 \%$ & $5.6 \%$ & $28.84 \%$ & $65.56 \%$ \\
2 & $4.5 \%$ & $2.29 \%$ & $23.58 \%$ & $74.13 \%$ \\
3 & $3 \%$ & $6.39 \%$ & $39.98 \%$ & $53.63 \%$ \\
4 & $1.5 \%$ & $0.67 \%$ & $31.21 \%$ & $68.12 \%$ \\
\hline
\end{tabular}

$\mathrm{Na}_{2} \mathrm{O}$ [23] in the original was $2.781 \%$ and this value increased to $5.517 \%$ by Sodium Carbonate activation. The percentage of $\mathrm{CaO}$ [23] in the original was $2.33 \%$ and this value decreased to $1.996 \%$ by $\mathrm{Na}_{2} \mathrm{CO}_{3}$ activation.

\subsection{X-Ray Diffraction Results}

The X-ray diffraction patterns of original Ain Al-Baida bentonite and $\mathrm{Na}_{2} \mathrm{CO}_{3}$ activated samples are illustrated in Figure 3. Montmorillonite was the main mineral; however, minor amounts of quartz, and palygorskite were identified by XRD. As seen from the activated sample patterns, the peak of quartz is very low, and the palygorskite was presented in samples.The main Montmorillonite reflections of diffraction are present in all samples.

The presence of these minerals can affect the transformation process of sodium to bentonite, and the rheological behavior of the raw material.

\subsection{Reological Results}

Imposing required standard specifications on Ain Al-Baida bentonite:

Seeking to a certain the degree of activation obtained for Ain Al-Baida bentonite we applied some standards specifications required for drilling fluid on activated bentonite [13]-[22] by measuring rheological properties (apparent viscosity, plastic viscosity, gel strength, lost filtrate, density, free swell index, liquidity limit and plasticity limit). These characteristics were measured for relative comparison as follows:

- First sample were Ain Al-Baida natural bentonite has not been activated [23] in previous paper.

- Second sample were Egyptian trade bentonite corresponding to standard specifications of drilling fluid as standard laboratory reference.

- Third sample was treated by addition sodium carbonate at different percentages $1.5 \%, 3 \%, 4.5 \%$, up to $6 \%$ adopting the approved published properties of US bentonite (Wyoming) as essential comparison reference.

Bentonite rheological properties given in Table 5 show an increase of sodium carbonate concentration leading to natural Ore dispersion, increase of apparent viscosity (A.V), decrease of plastic viscosity (P.V) and the loss filtrate (WL).

This behavior shows the natural raw capacity for transformation quantity of sodium from sodium carbonate which gives the best results with standard specification API spec. 13A, 1993 [14].

It can be seen that dispersion represents an apparent viscosity increasing values from 19 to $24.5 \mathrm{cp}$ of bentonite match the standard specifications. Also the filtration values are less than the upper limit from 8 to $11 \mathrm{ml}$ and $\mathrm{pH}$ 9.5, based on standard specifications, the ratio between Y.P/P.V was ranged 0.88 to 1.21 , it is means the behavior of drilling fluids confirm the Bingham plastic and power -law rheological models . Relationship between modified free swell index and sodium carbonate concentration in bentonite showing that modified free swell index often increase as ratio of sodium carbonate concentration increased to extent that swelling of crystals and expand of internal bentonite layers resulting swelling (Norrish \& Qurik 1954) [24].

Increasing concentration of sodium carbonate dissolves sodium ion leaving some negative charge units for montmorillonite Sand osmotic pressure of the swelling becomes dominant to improve the free swelling of bentonite.

Mechanical grinding [25] used help in work lot guidance tests then speed comparison between their results accessing best conditions of activation bentonite process technically and economically as in Figure 4.

Results of free swell test of Ain Al-Baida bentonite are summarized in Table 6. Swelling volumes were recorded within 24 hours after free dispersion. The free swell of powdered bentonite, as defined by ASTM D422, 


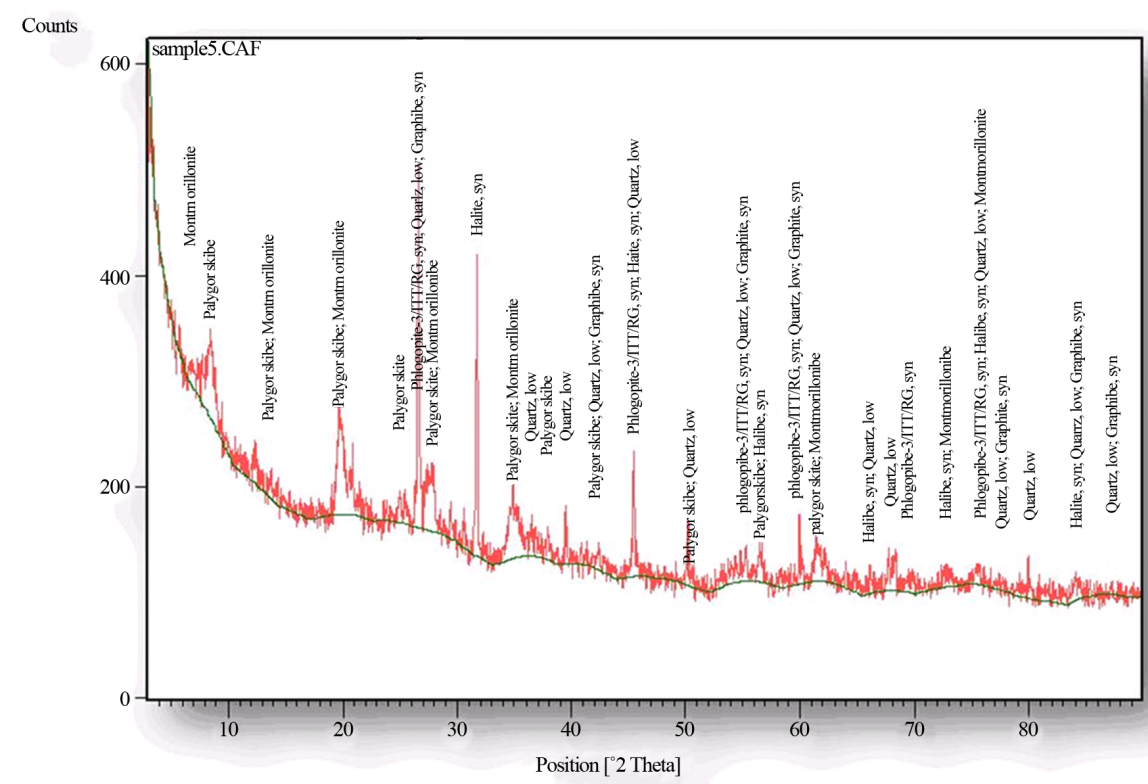

Figure 3. X-ray analysis of clay minerals on Ain Al-Baida samples.

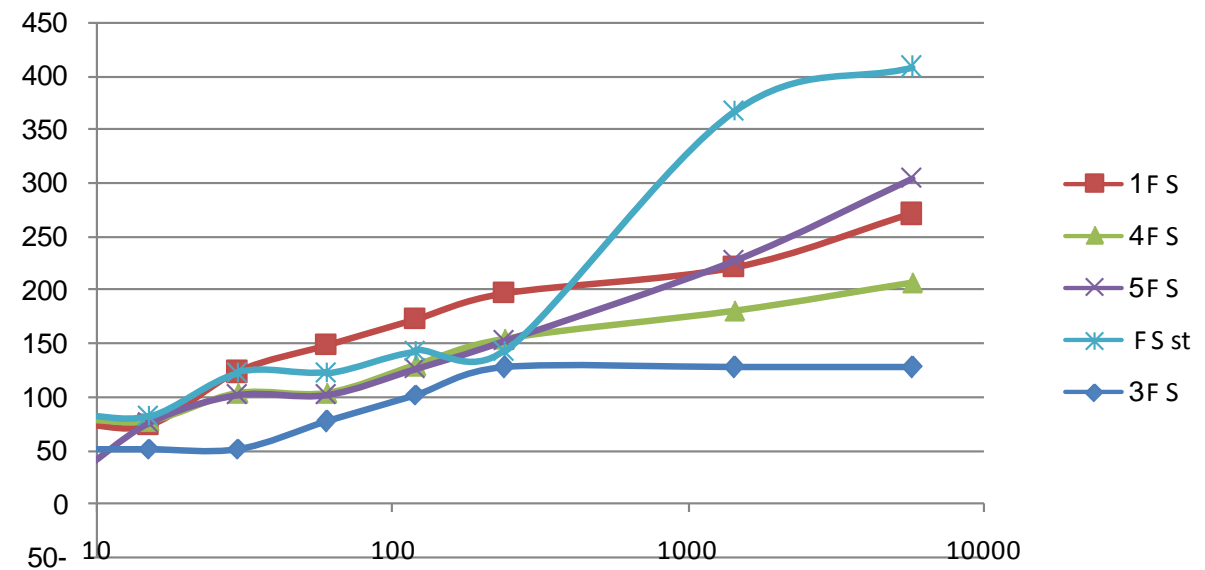

Figure 4. Free swelling index with concentration sodium carbonate.

Table 5. Bentonite( Ore) rheological properties.

\begin{tabular}{|c|c|c|c|c|c|c|c|c|c|c|c|}
\hline \multirow{2}{*}{$\begin{array}{l}\text { Sample } \\
\text { Number }\end{array}$} & \multirow{2}{*}{ Viscosity S } & \multicolumn{2}{|c|}{ Viscometer dial reading } & \multirow{2}{*}{ A.V cp } & \multirow{2}{*}{ P.V ср } & \multirow{2}{*}{$\begin{array}{c}\text { Y.P } \\
\mathrm{lb} / 100 \mathrm{ft}^{2}\end{array}$} & \multicolumn{2}{|c|}{ Gel lb/100ft ${ }^{2}$} & \multirow{2}{*}{$\begin{array}{c}\text { Filtrate } \\
\mathrm{lb} / 100 \mathrm{ft}^{2}\end{array}$} & \multirow{2}{*}{$\begin{array}{l}\text { Y.P/ } \\
\text { P.V }\end{array}$} & \multirow{2}{*}{$\mathrm{PH}$} \\
\hline & & $600 \mathrm{rpm}$ & $300 \mathrm{rpm}$ & & & & $10 \mathrm{~s}$ & $10 \mathrm{~m}$ & & & \\
\hline 1 & 40 & 38 & 26 & 19 & 12 & 7 & 3 & 5 & 8 & 0.58 & 8.5 \\
\hline 2 & 40 & 38 & 24 & 19 & 14 & 10 & 3 & 4 & 9 & 0.71 & 8.5 \\
\hline 3 & 45 & 49 & 32 & 24.5 & 17 & 15 & 3 & 5 & 11 & 0.88 & 9.5 \\
\hline 4 & 42 & 44 & 30 & 22 & 14 & 16 & 3 & 5 & 10 & 1.14 & 9.5 \\
\hline 5 & 42 & 45 & 31 & 22.5 & 14 & 17 & 3 & 5 & 10 & 1.21 & 9.5 \\
\hline 6 & 44 & 48 & 32 & 22 & 16 & 16 & 3 & 5 & 10 & 1 & 9.5 \\
\hline
\end{tabular}

2002, is $100 \mathrm{ml} / 10 \mathrm{~g}$, the free swell ranged between $180.6 \%$ to $227.7 \%$. After 4 days, the observation was also made, when samples were dispersed, the swelling bentonite has free swell values ranges between $271 \%$ to $303.6 \%$. 
Table 6. Free swelling results.

\begin{tabular}{|c|c|c|c|c|c|c|c|c|c|c|c|c|c|c|c|}
\hline \multirow{3}{*}{$\begin{array}{c}\text { sample \# } \\
\text { Gs } \\
\text { time (min) }\end{array}$} & \multicolumn{3}{|c|}{1} & \multicolumn{3}{|c|}{2} & \multicolumn{3}{|c|}{3} & \multicolumn{3}{|c|}{4} & \multicolumn{3}{|c|}{5 st. } \\
\hline & \multicolumn{3}{|c|}{2.46} & \multicolumn{3}{|c|}{2.54} & \multicolumn{3}{|c|}{2.58} & \multicolumn{3}{|c|}{2.53} & \multicolumn{3}{|c|}{2.04} \\
\hline & 1 & V.-V & F S1 & 2 & V.-V & F S3 & 3 & V.-v & F S4 & 4 & V.-V & F S5 & st. & V.-V & F S st \\
\hline 0 & 11 & & & 16 & & & 15 & & & 13 & & & 12 & & \\
\hline 0.1 & 11 & 0 & 0 & 16 & 0 & 0 & 15 & 0 & 0 & 13 & 0 & 0 & 12 & 0 & 0 \\
\hline 0.2 & 11 & 0 & 0 & 16 & 0 & 0 & 15 & 0 & 0 & 13 & 0 & 0 & 12 & 0 & 0 \\
\hline 0.5 & 11 & 0 & 0 & 16 & 0 & 0 & 15 & 0 & 0 & 13 & 0 & 0 & 12 & 0 & 0 \\
\hline 1 & 11 & 0 & 0 & 17 & 1 & 25.4 & 15 & 0 & 0 & 13 & 0 & 0 & 14 & 2 & 40.8 \\
\hline 2 & 12 & 1 & 24.6 & 18 & 2 & 50.8 & 16 & 1 & 25.8 & 13 & 0 & 0 & 15 & 3 & 61.2 \\
\hline 4 & 13 & 2 & 49.2 & 18 & 2 & 50.8 & 17 & 2 & 51.6 & 13 & 0 & 0 & 15 & 3 & 61.2 \\
\hline 8 & 14 & 3 & 73.8 & 18 & 2 & 50.8 & 18 & 3 & 77.4 & 14 & 1 & 25.3 & 16 & 4 & 81.6 \\
\hline 15 & 14 & 3 & 73.8 & 18 & 2 & 50.8 & 18 & 3 & 77.4 & 16 & 3 & 75.9 & 16 & 4 & 81.6 \\
\hline 30 & 16 & 5 & 123 & 18 & 2 & 50.8 & 19 & 4 & 103.2 & 17 & 4 & 101.2 & 18 & 6 & 122.4 \\
\hline 60 & 17 & 6 & 148 & 19 & 3 & 76.2 & 19 & 4 & 103.2 & 17 & 4 & 101.2 & 18 & 6 & 122.4 \\
\hline 120 & 18 & 7 & 172 & 20 & 4 & 101.6 & 20 & 5 & 129 & 18 & 5 & 126.5 & 19 & 7 & 142.8 \\
\hline 240 & 19 & 8 & 197 & 21 & 5 & 127 & 21 & 6 & 154.8 & 19 & 6 & 151.8 & 19 & 7 & 142.8 \\
\hline 1440 & 20 & 9 & 221 & 21 & 5 & 127 & 22 & 7 & 180.6 & 22 & 9 & 227.7 & 30 & 18 & 367.2 \\
\hline 5760 & 22 & 11 & 271 & 21 & 5 & 127 & 23 & 8 & 206.4 & 25 & 12 & 303.6 & 32 & 20 & 408 \\
\hline
\end{tabular}

\section{Liquid Limit of Bentonite and Soil Bentonite Mixtures}

Due to open and hydrated interlayer in Ore Ain AL-Baida bentonite, cations may be present within the interlayer to balance negative charges. When exposed to water, water move freely between the layers, leading to interlayer swelling. Montmorillinte will have a cation exchange capacity of around 53 to $83 \mathrm{Meq} / 100 \mathrm{~g}$, it is a highly colloidal and plastic clay with possibility of swelling to about 10 times it is original volume when exposed in water, plate like bentonite Ain AL-Baida [23] can provide a suitable potential for surface area ,and good activities (AC $=0.98$ to 1.48). Typical characteristics of principal clay minerals are shown in Table 7 .

Influence of physico-Chemical characteristics of swelling materials may be explained by the relationship between atterberg limits and clay fraction and rheological characteristics of swelling bentonite in common natural clay.

In the description of fined - grained soils, water content corresponding to the boundaries between the state of consistency, are called Atterberg Limits (Liquid limit LL and plastic Limit LP). Figure 5 illustrated the results of plasticity chart and relation between index and clay fraction (Percentage of particles $75 \mu \mathrm{m}$ ), range for the liquid limit between (83\% to $140 \%$ ). This means that the amount of attracted Water will be suitable influenced by the amount of clay that is present Ore Ain AL-Baida bentonite.

The plastic limit of Ore Ain Al-Baida bentonite range between (39\% to 48\%), he flocculated samples have just moderately plastic limit, that it means the clayey silt of low plasticity. From Table 7, we have low to me$\operatorname{dium}(0.53<\mathrm{Ac}<0.55)$ and medium to high $(0.98<\mathrm{Ac}<1.48)$, reflecting the medium to high content of clay minerals. It is means that the behavior of drilling fluids confirms the Bingham plastic and power -law rheological models.

Liquid limit of bentonite depends on the net interparticle repulsive forces [26] [27] of atom between clay particles and the strength of interlaced atoms that responsible for montmorillonite swelling where Figure 5 represent free swelling with percentage of clay ore bentonite.

A correlation between liquid limit and free swelling is expected. The relationship between liquidity limit and bentonite free swelling shows clear positive correlation between the two parameters. The Figure 6 shows an increase in liquidity limit with an increase in the free swell, the interparticle can be explained in terms of the interaction volume of clay atom unit mass known as the volume between individual granules or a group of particles 


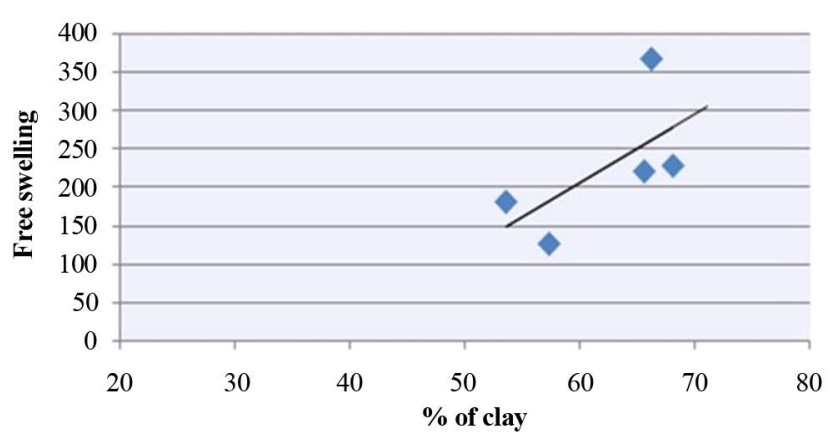

Figure 5. Represent free swelling with percentage of clay ore bentonite.

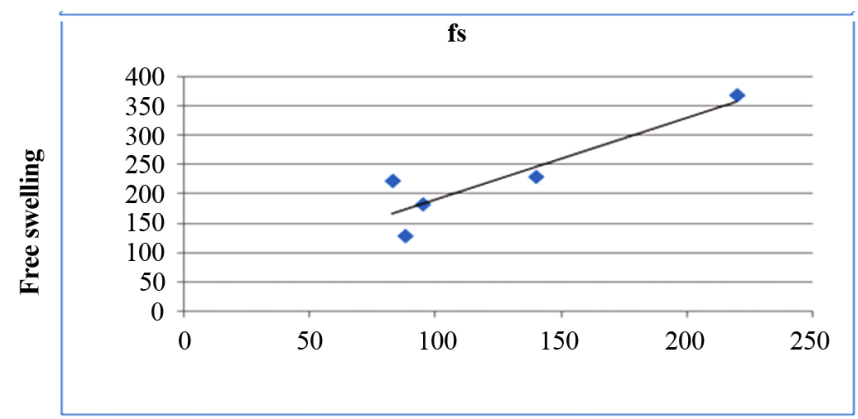

Liquid limit

Figure 6. Shows increase in liquidity limit with an increase in the free swell.

Table 7. Typical Characteristics of principal clay minerals of Ain AL-Baida bentonite.

\begin{tabular}{ccccc}
\hline Number samples & Liquid Limit \% & Plastic Limit \% & Activities Ac & CF\% \\
\hline $1-$ & 83 & 47 & 0.543 & 65.56 \\
$2-$ & 88 & 48 & 0.539 & 74.13 \\
$3-$ & 95 & 42 & 0.98 & 53.63 \\
$4-$ & 140 & 39 & 1.48 & 68.12 \\
5-standard sample & 220 & 45 & 0.678 & 66.29 \\
\hline
\end{tabular}

that interfere in the movement of the adjacent particles units.

When swelling increase volumetric interaction will increase and granules get free movement in higher water content causing distance increase between atoms and thereby extent liquidity limit increase. There is a positive match between liquidity limit of soil-bentonite mixture and free swelling of bentonite which can be explained through influence of non-swelling granules exist in the mixture 2006.

The relationship between liquidity limit and sodium exchange rate to bentonite is existed. Free swelling of bentonite with sodium rate exchange and liquidity limit of bentonite have increased linearly with increase in sodium proportion exchange, but in little range, while appeared it increase in less percentage with exchange sodium percentage existence. On the other hand liquidity limit of bentonite soil mixture has increased little percentage with increment of sodium exchange that can be modified through volumetric interaction at low values of sodium exchange causing prevail of bilateral positive charge ions to inhibit the spread of double layer montmorillinte granules maintaining volumetric interaction of granules low [24]. That results decrease in liquidity limit values and increase in sodium exchange proportion which is responsible for rising spread of montmorillonite granules double layer and volumetric interaction increase of these granules thus improves liquidity limit of bentonite.

\section{Conclusion}

A correlation between liquid limit and free swelling is expected. The relationship between liquidity limit and 
bentonite free swelling shows clear positive correlation between the two parameters. Figure 6 shows an increase in liquidity limit with an increase in the free swelling. Inter particle can be explained in terms of the interaction volume of clay atom unit mass known as the volume between individual granules or a group of particles that interfere in the movement of the adjacent particles units. When swelling increase volumetric interaction will increase and granules get free movement in higher water content causing distance increase between atoms and thereby extent liquidity limit increase. There is positive match between liquidity limit of soil-bentonite mixture and free swelling of bentonite which can be explained through influence of non-swelling granules exist in the mixture 2006. Free swelling of bentonite with sodium rate exchange and liquidity limit of bentonite have increased linearly with increase in sodium proportion exchange, but in little range, while it appeared that increase in less percentage with exchange sodium percentage existence. On the other hand, liquidity limit of bentonite soil mixture has increased with increment of sodium exchange that can be modified through volumetric interaction at low values of sodium exchange causing prevail of bilateral positive charge ions to inhibit the spread of double layer montmorillinte granules maintaining volumetric interaction of granules low [24]. Thus that will result a decrease in liquidity limit values and increase in sodium exchange proportion which is responsible for rising spread of montmorillonite granules double layer and increase volumetric interaction of these granules causing improvement in liquidity limit of bentonite.

\section{Acknowledgements}

The authors would like to thank eng. Kholoud S. Al-Ajlouni for her assistance and help.

\section{References}

[1] Bates, R.L. (1969) Clay in Geology of Industrial Rock \& Minerals. Dover Pub. Inc., New York, 117-151.

[2] Grim, R. (1968) Applied Clay Mineralogy. MC. Graw-Hill Book.

[3] Alali, J.M. (1991) Assessment of Azraq Diatomaccous Clay, Jordan. MSc Thesis, Leicester University, 85 p.

[4] Alali, J.M. and Abu Salah, A. (1993) Exploration for Bentonite and Other Minerals in Azraq Depression. Int. Rep. NRA, Amman, 4 Volumes.

[5] Khoury, H. (1980) Mineralogy and Origin of Azraq Clay Deposits Dirasat. University of Jordan, Amman, 21-31.

[6] Khoury, H. (1989) Clay and Clay Minerals in Jordan. Department of Geology University of Jordan, Amman.

[7] Nawasreh, M. (2001) Azraq Clay Minerals in Investigation of Jordanian Minerals. Cardiff University, 327 p.

[8] Sivapullaiah, et al. (1987) Suggested a New Method for Obtain a Modified Free Swell Index for Clays.

[9] Sivapullaiah, P.V. and Savitha, S. (1999) Index Properties of Ililte-Bentonite Mixtures in Electrolyte Solutions Technical Note. 22.

[10] Grim and Guven (1978) Bentointe Geology Mineralogy Use and Physical Properties. Elsevier, New York, 256.

[11] American Society for Testing and Materials (2002) Standard Test Method for Particle-Size Analysis of Soils. D DASTM, Philadelphia, 422-463.

[12] Khoury, H. (1995) Mineralogy and Origin of Azraq Clay Deposits. Dirassat, 7, 21-31.

[13] Kemp, S. (1995) Initial Laboratory Characterization of Clay-Bearing Rocks from Jordan. British Geological Survey Technical Report No. WG/95/16R.

[14] Dallas, A. (1993) Standard Procedure for Testing Drilling Fluids. API R.P 13.

[15] Drilling Mud Date Book. NL Baroid, Houston, 1954.

[16] Magcobar Division—Oilfield Products Group—Dresser Industries (1977) Drilling Fluid Engineering Manual.

[17] Applied Mud Technology, IMOC Services a Division of Halliburton Company, Houston.

[18] Grim, M.R. (1974) Drilling Fluids Technology. Exxon. Co., Houston.

[19] Bourgoyne Jr., A.T., Millheim, K.K., Chenevert, E.M. and Young Jr., F.S. (1991) Applied Drilling Engineering (SPE Textbook Series, Volume 2). Society of Petroleum Engineers, Richardson.

[20] Irawan, S. and Samsuri, A. (2007) Utilization of Treated Malaysian Local Bentonite for Drilling Mud Material Cost Saving.

[21] Moore, D.M. and Reynolds, R.C. (1984) X-Ray Diffraction and the Identification and Analysis of Clay Minerals. Oxford University Press, New York.

[22] Amorim, L.V., Gomes, C.M., Lira, H. de L., França, K.B. and Ferreira, H.C. (2004) Bentonites from Boa Vista, Brazil: 
Physical, Mineralogical and Rheological Properties. Materials Research, 7, 583-593. http://dx.doi.org/10.1590/S1516-14392004000400012

[23] Mahasneh, M.A. and Saleh, S.K. (2012) Evaluation of Jordanian Bentonite Performance for Drilling Fluid Applications. Contemporary Engineering Sciences, 5, 149-170.

[24] Norrish, K. and Qurik, J. (1954) Crystalline Swelling of Montmorillonite Use of Electrolyte to Control Swelling. Nature, 173, 255-257. http://dx.doi.org/10.1038/173255a0

[25] Al-Maghrabi, M.N. and Aboushook, M. (2008) Activation of Khulais Bentonite Using Finegrinding Technique. Journal of King Abdulaziz University-Engineering Science, 19, 37-55.

[26] Warkentin, B.P. (1961) Interpretation of the Upper Plastic Limit of Clays. Nature, 190, 287-288. http://dx.doi.org/10.1038/190287a0

[27] Warkentin, B.P. and Yong, R.N. (1960) Shear Strength of Montmorillonite and Kaolonite Related to the Interparticle Forces. Clays and Clay Minerals, 9, 210-218. http://dx.doi.org/10.1346/CCMN.1960.0090111 